\title{
mars and tousled-like kinase act in parallel to ensure chromosome fidelity in Drosophila Hsing-Hsi Li ${ }^{1}$, Chuen-Sheue Chiang2 ${ }^{2}$ Hsiao-Yu Huang1 and Gwo-Jen Liaw*1
}

\author{
Address: ${ }^{1}$ Department of Life Sciences and Institute of Genome Sciences, National Yang-Ming University, Taipei, 112 Taiwan, ROC and ${ }^{2}$ Centers \\ for Disease Control, Department of Health, Taipei, 115 Taiwan, ROC \\ Email: Hsing-Hsi Li - violincello48@gmail.com; Chuen-Sheue Chiang - cschiang10@cdc.gov.tw; Hsiao-Yu Huang - windcmsj@gmail.com; \\ Gwo-Jen Liaw* - gjliaw@ym.edu.tw \\ * Corresponding author
}

Published: I June 2009

Journal of Biomedical Science 2009, 16:5 I doi:10.1 186/|423-0|27-16-51

This article is available from: http://www.jbiomedsci.com/content//6/I/5 I

(C) 2009 Li et al; licensee BioMed Central Ltd.

This is an Open Access article distributed under the terms of the Creative Commons Attribution License (http://creativecommons.org/licenses/by/2.0), which permits unrestricted use, distribution, and reproduction in any medium, provided the original work is properly cited.
Received: 24 October 2008

Accepted: I June 2009

\begin{abstract}
Background: High levels of Hepatoma Up-Regulated Protein (HURP) and Tousled-Like Kinase (TLK) transcripts are found in hepatocellular carcinoma. HURP overexpression induces anchorageindependent growth of 293-T cells and enhances a rough-eye phenotype resulting from t/k overexpression in Drosophila. In addition, both HURP and Mars, a Drosophila HURP sequence homologue, promote polymerization of mitotic spindles. Thus, the genetic interaction of mars with tk might be required for accurate chromosome segregation.
\end{abstract}

Methods: To reveal whether chromosome fidelity was decreased, the frequency of gynandromorphy, an individual with both male and female characteristics, and of non-disjunction were measured in the progeny from parents with reduced mars and/or tk activities and analyzed by Student's $t$-test. To show that the genetic interaction between mars and $t / k$ is epistatic or parallel, a cytological analysis of embryos with either reduced or increased activities of mars and/or tlk was used to reveal defects in mitotic-spindle morphology and chromosome segregation.

Results: A significant but small fraction of the progeny from parents with reduced mars activity showed gynandromorphy and non-disjunction. Results of cytological analysis revealed that the decrease in chromosome fidelity was a result of delayed polymerization of the mitotic spindle, which led to asynchronous chromosome segregation in embryos that had reduced mars activity. By removing one copy of tousled-like kinase (tlk) from flies with reduced mars activity, chromosome fidelity was further reduced. This was indicated by an increased in the non-disjunction rate and more severe asynchrony. However, the morphology of the mitotic spindles in the embryos at metaphase where both gene activities were reduced was similar to that in mars embryos. Furthermore, $t$ k overexpression did not affect the morphology of the mitotic spindles and the cellular localization of Mars protein.

Conclusion: Chromosome fidelity in progeny from parents with reduced mars and/or tlk activity was impaired. The results from cytological studies revealed that mars and tlk function in parallel and that a balance between mars activity and tlk activity is required for cells to progress through mitosis correctly, thus ensuring chromosome fidelity. 


\section{Background}

Genetic instability is a hallmark of cancers and occurs at two levels. First, defects in the DNA repair system increase the mutation rate due to an inability to correct errors resulting from DNA damage or DNA replication. Second, missegregation of chromosomes during mitosis or meiosis leads to aneuploidy or translocations. Chromosome segregation is controlled by groups of proteins acting together in order to coordinate the M-phase progression [1-3]. Mutation of a protein playing a key role during chromosome separation would be expected to lead to cell death. However, when a protein has a loss-of-function mutation and the protein plays a subtle role in mitosis, this may result in viable cells that have chromosome abnormalities and in neoplasia [4].

In the postgenomic era, along with molecular biology tools that have been developed to explore global gene expression profiles, database mining using bioinformatics has revealed key differences in genes expressed under various conditions. One such example is the comparison of genes expressed in human hepatocellular carcinoma (HCC) versus normal liver cells [5,6]. One gene found to be up-regulated at the G2/M transition in human 293T cells from these profiling experiments is Hepatoma Up-Regulated Protein (HURP), which encodes a protein that contains a guanylate kinase associated protein domain (GKAP) [7]. This domain was initially identified in a protein associated with Postsynaptic density-95 (PSD-95), a member of the membrane-associated guanylate kinase homologue (MAGUK) family. MAGUKs play roles in cytoskeleton signaling and at the synaptic/epithelial cell junctions [8-10]. Overexpression of HURP induces anchorage-independent growth of human $293 \mathrm{~T}$ cells, suggesting that it is involved in tumorigenesis [7].

When cells are ready to divide, they undergo several morphological changes, including centrosome separation, nuclear envelope breakdown and chromosome condensation. These events are coordinately controlled by several highly conserved kinases, such as Cdc2/CyclinB, Polo-like and Aur-A/Ipl1. AUR-A mediates Ran-GTP activity [11], which regulates the stability and activity of HURP by controlling the accessibility of the protein's microtubulebinding domain $[1,6]$. HURP promotes polymerization of the spindle microtubules near the kinetochore in order to generate sufficient tension across the sister kinetochores [12-14]. In addition, HURP drives the formation of a tubulin (Tub) sheet that wraps around ends of microtubule bundles to strengthen the mitotic spindle [15].

We conducted a gain-of-function screen to search for human genes across 76 selected genes that are up-regulated in HCC. The aim was to identify genes that modify the rough-eye phenotype caused by tousled-like kinase (tlk) overexpression. HURP was found to be one such gene. The tousled gene in Arabidopsis thaliana encodes a Ser/Thr kinase and is the founding member of the Tlk subfamily [16]. Members in this subfamily are highly conserved from protozoa to mammals [16-20]. Tlks are thought to participate in cancer development; this is based on the facts that human TLKs are also up-regulated in a number of cancers, including HCC [21] and that Tlk function during the $S$ phase of the cell cycle in vertebrates [20]. In humans and fly, TLK2 and Tlk, respectively, physically interact with Asf1, a factor required for chromatin assembly $[17,22]$. Furthermore, in Caenorhabditis elegans and Trypanasoma brucei, Tlk- 1 is a substrate of and mediates activation of the Aur-B kinases [3,19,23], the activity of which promotes amphitelic attachment (each sister kinetochore binds to one of the two spindle microtubules arising from opposite poles) rather than monotelic or syntelic attachment (only one or both sister kinetochores bind to spindle microtubules arising from the same pole) during chromosome congression (the syn-to-amphitelic transition) $[24,25]$.

In D. melanogaster, both mars and vulcan ( $v l c)$ encode GKAP-containing proteins [26,27]. Neither Mars nor Vlc shows high sequence homology to HURP except for their GKAP domains. Although the similarity of the GKAP domains between Vlc and HURP is higher than that between Mars and HURP, the relative positions of several other conserved domains, which are found in these three proteins when vertebrates and Drosophila are compared, are more similar between Mars and HURP. This contrasts with Vlc and HURP, where there is little similarity in these domains when the situation is compared to Mars and HURP (Fig. 1). Specifically, putative destruction boxes (D boxes, RXXL) are found in the domain a of HURP and in the domains $\mathrm{c}$ and $\mathrm{d}$ of Mars (Fig. 1) and the latter two are in the region responsible for Mars degradation [28,29]. In addition, mars overexpression induces a metaphase arrest and results in abnormal chromosome figures in cells of the eye disc, indicating that Mars is required for accurate chromosome segregation [29]. Furthermore, Mars binds to protein phosphatase 1 to dephosphorylate DrosophilaTransforming acidic coiled-coil protein that stabilizes microtubules [30]. In this study, we characterized the genetic interaction between mars and $t k$ and assessed their involvement in chromosome fidelity.

\section{Methods}

\section{Drosophila strains and fly genetics}

Lines $w^{*} ; P\{E P\} d r k^{E P 2477} / C \gamma O, D f(2 R) C X 1 w^{12} b^{1} p^{1} / S M 1$ and $w^{67 c 23} P\left\{w^{+M C}=l a c W\right\} t^{-G 0113 a, b, c}$ were obtained from the Szeged and Bloomington Stock Center. Tan and coworkers has reported that $w^{*} ; P\{E P\} d r k^{E P 2477} / C \gamma O$ is a hypomorph of mars, designated as $\operatorname{mars}^{P}[30]$. A $d r k$ hypomorph, $d r k^{R 1} / C y O[31], y^{1} w^{1} s n^{3}, P\left\{w^{+M C}=U A S T-t l k\right\} \# 0$ 
A

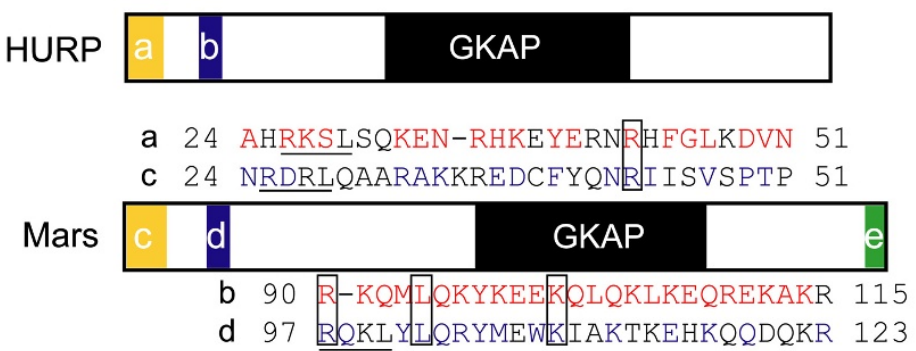

VIc

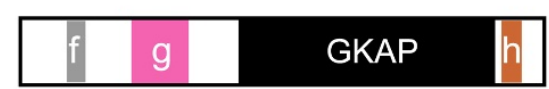

B

$\left.\begin{array}{ll}\begin{array}{l}\text { human } \\ \text { mouse }\end{array} & \text { AHRKSLSQKEN-RHKEYERNRHFGLKDVN } \\ \text { rat } & \text { AHRKSLSQKEN-RHRVYERNRHFGLKDVN } \\ \text { chicken } & \text { ARRKSMLQKEN-RHKMFEKGROFGLTDVN } \\ \text { mel } & \text { NRDRLQAARAKKREDCFYQNR I ISVSPTP } \\ \text { sim } & \text { NRDRLHAARAKKRDDCFYQNRIISVSPTP } \\ \text { pseu } & \text { NRELQKAARAKQREDRFQSNR I ISVSPTP } \\ \text { vir } & \text { NRERQSVVRTKLSDELFQSNRI IKDIGPST }\end{array}\right\}$ domain c

human

mouse

rat

chicken

mel

sim

pseu

vir

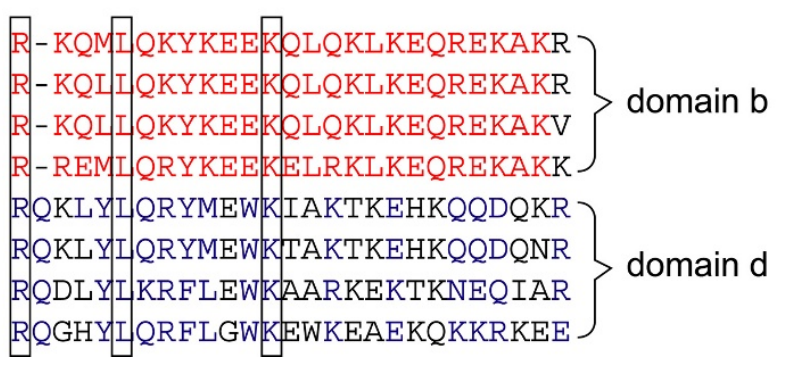

Figure I

Similarity between Mars and HURP is higher than that between Vulcan and HURP. (A) Diagrams show conserved domains in HURP, Mars and Vulcan (Vlc). The sizes of the GKAP domains in HURP, Mars and Vlc are 297 (30I-597), 315 (452-766) and 323 (266-588) amino acids, respectively. The amino acid sequences of the HURP orthologues in human, mouse, rat and chicken were aligned to identify conserved domains other than the GKAP domain. Two conserved domains, a and $b$ with similarities of $79 \%$ and $92 \%$, were found using the ClustalW program. Similarly, three conserved domains in Mars (c-e) and Vlc (f-h) among Drosophila species including melanogaster, simulans, pseudoobscura and virilis were identified. Similarities of these three domains in Mars and Vlc ranged from $57 \%$ to $73 \%$ and from $90 \%$ to $95 \%$, respectively. Paired amino acid sequences of domains $\mathrm{a} / \mathrm{c}$ and b/d are shown. Conserved amino acids in the HURP or Mars orthologues are indicated by red and blue letters (see sequence alignments in panel B). The highly conserved amino acids among the eight species are boxed. Putative destruction boxes, RXXL, are underlined. (B) The conserved domains in the HURP orthologues from vertebrates (human, mouse, rat and chicken) and in the Mars orthologues from Drosophila species, including melanogaster (mel), simulans (sim), pseudoobscura (pseu) and virilis (vir) were separately identified using the CustalW program. Sequences of the conserved domains were aligned manually to identify highly conserved amino acid residues (boxed). Conserved amino acids in the HURP and Marsorthologues are indicated by red and blue letters.

(abbreviated as UAST-tlk) and $w$ tlk ${ }^{414} / F M 7$ [17] were generous gifts from Drs. E. Hafen, H.Y. Sun and F. Karch.

Starting with $w^{67 c 23} P\left\{w^{+M C}=l a c W\right\} t l k^{G 0113 a}$ in which the other two P-element inserts were segregated by meiotic recombination, a duplication line, $w^{67 c 23} t t^{27}$, with another copy of $P\left\{w^{+M C}=l a c W\right\}$ inserted at the 5'end of Rala, was generated. Using P-element imprecise excision, a deficiency, $w^{67 c 23} t k^{27-9}$, with a deletion between the $5^{\prime}$ end of Rala and $4^{\text {th }}$ exon of tlk-RB, was obtained. Transgenic fly lines carrying a $P\left\{w^{+M C}=U A S P-t l k\right\}$ transgene (abbreviated as UASP-tlk) were generated by inserting the 
tlk coding region in the GH07910 EST clone into pUASP [32] and then the resulting plasmid DNA was transformed into flies using P-element mediated germ-line transformation $[33,34]$. To express tlk in the germ line, females of a selected UASP-tlk line were crossed with GAL4-GCN4 males [35]. The resulting females carrying both transgenes were crossed with UAST-tlk males for the collection of embryos, which are described here as GCN4>tlk embryos.

The $w^{*} ; P\{E P\} d r k^{E P 2477} / C \gamma O$ strain obtained from the stock center was homozygous lethal. To eliminate the possible existence of a second-site mutation, meiotic recombination was used [36]. After five rounds of meiotic recombination, some newly generated lines were homozygous viable and P-element insertion was confirmed by PCR.

\section{Immunoblotting}

To determine the level of Mars protein in syncytial blastoderm embryos, a collection of metaphase embryos as described by Su (2000) was made and this collection was used to perform immunoblotting. In brief, embryos from 0 to 1 hour were collected and aged for 1.5 hour. The embryos were dechorionated in bleach, fixed in methanol for 5 minutes and stained with $40 \mathrm{pg} / \mathrm{ml}$ of Hoechst 33342 (Sigma/Aldrich, Inc) in $1 \times$ PBS. Syncytial blastoderm embryos at metaphase were picked out under an inverted fluorescence microscope (Leica Model DM Illinois, USA) [37]. Protein pools from 30 embryos were separated using $8 \%$ SDS polyacrylamide gels. The proteins in the SDS gels were transferred onto PVDF membrane and Mars was detected using anti-Mars antibody (1:5000; generously provided by Dr. S.-S. Fan [38]). After incubation with the secondary antibody, a chemilluminescent assay kit (Western lighting ${ }^{\mathrm{TM}}$, Blossom Biotechnologies, Inc, Taiwan) was used to detect the protein [39].

\section{Immunohistochemical analysis}

Embryos were fixed in 37\% formaldehyde at room temperature (RT) for $5 \mathrm{~min}$. Eye-antennal discs of late third instar larvae were dissected in $1 \times$ PBS and then transferred into $1 \times$ PBS containing $4 \%$ paraformaldehyde for $30 \mathrm{~min}$. The embryos or eye-antennal discs were washed with $1 \times$ PBST $(0.3 \%$ Triton X-100 in $1 \times$ PBS) and incubated with a blocking solution ( $1 \%$ BSA in $1 \times$ PBST) prior to incubation with various primary antibodies, anti-phosphohistone H3 (Upstate) (1:200 dilution), $\alpha$-Tub (Sigma/ Aldrich, Inc) (1:200 dilution), $\gamma$-Tub (Sigma/Aldrich, Inc) (1:200 dilution), or Mars (1:400 dilution), at either $4{ }^{\circ} \mathrm{C}$ overnight or at RT for 2 hours. Localization of the proteins was detected by incubating with secondary antibodies conjugated with either Cy3 or FITC (Jakson ImmunoResearch Lab) (1:200 dilution) at $4{ }^{\circ} \mathrm{C}$ overnight or at RT for 2 hours. The contours of the photoreceptor clusters in the eye discs were stained with Phalloidin-Tetramethylrhod- amin B isothiocyanate (Phalloidin-TRITC) (Invitrogen Molecular Probe) (1:80 dilution) for 1 hour. Embryos were incubated with $4 \mathrm{ng} / \mathrm{ml}$ of Hoechst 33342 (Sigma/ Aldrich, Inc) to stain their chromosomes. The embryos or eye-antennal discs were mounted in a mounting medium (20 mM Tris-HCl pH 8.8, 50\% glycerol and 4\% n-propyl gallate) and viewed under a Leica confocal microscope (Model TCS-SP2) [39,40].

To determine the density of the mitotic spindles at metaphase, anaphase or telophase, as represented by the fluorescence intensity of the mitotic spindle, the green channel of the selected images was converted into grayscale and the gray value surrounding the mitotic spindle was adjusted to around $80 \%$ using Photoshop. For each mitotic phase, the intensity of one 10 by 10 pixel square of one spindle from each nucleus was measured using Image J http://rsb.info.nih.gov/ij. Six nuclei in twelve embryos at nuclear cycles 10 or 11 (as shown in Fig. 2D) were randomly chosen for the measurements, which were used to obtain an average intensity. The average value was then normalized against the background, which was the average value from ten 10 by 10 pixel squares outside of and surrounding the mitotic spindle. This produced values in arbitrary units (au) of fluorescence intensity. The length of the mitotic spindle from centrosome to centrosome of the same nuclei was also measured. The statistical significance of differences in the density and the length of the assessed mitotic spindles were determined using the Student's $t$-test.

\section{Results \\ Mars localizes on the mitotic spindle at metaphase and anaphase}

Immunostaining was performed to reveal the localization of endogenous Mars protein. Throughout the syncytial blastoderm stage, a low level of punctate staining was observed, indicating that a low level of Mars was uniformly present in the cytoplasm of the embryos (data not shown). In addition to this low level and uniform distribution of Mars protein, at the onset of mitosis, when the centrosome is divided into two, a high level of Mars was detected in the nucleus (Fig. 3). During metaphase and anaphase, Mars was predominantly localized on the mitotic spindles, a cellular structure essential for faithful distribution of chromosomes into the two daughter cells $[41,42]$, but not on the centrosomes or the astral microtubules. At telophase, a high level of Mars colocalized with the de-condensing chromosomes. The subcellular localizations of Mars at $M$ phase are consistent with other reports [30,43], indicating that Mars functions on the mitotic spindles. 


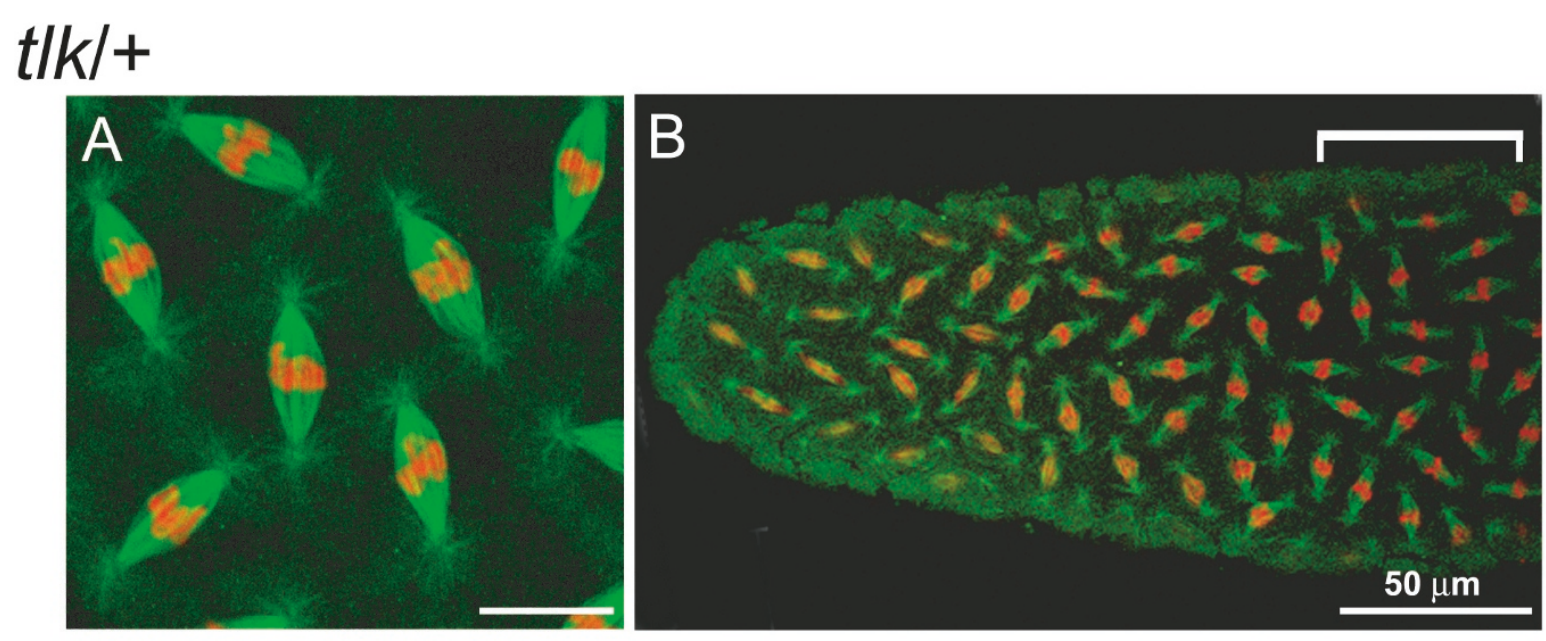

\section{mars}
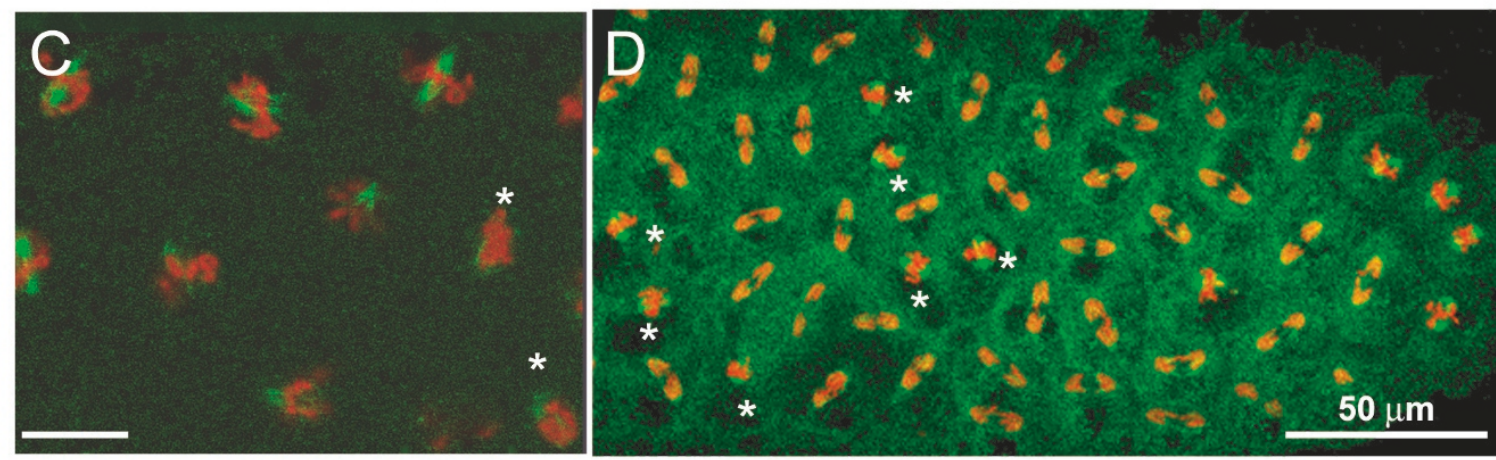

\section{tlk/+; mars}

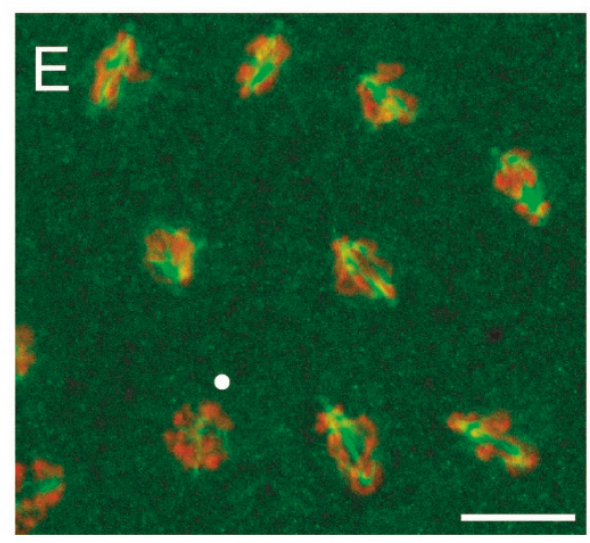

Figure 2

Asynchronous mitosis occurs in mars and t/k/mars embryos at the non-permissive temperature. Embryos from $t k^{\Delta l 4 /+}(A$ and $B), \operatorname{mars}^{P}(C$ and $D)$ and $t k^{\Delta l 4 /+}$; $\operatorname{mars}^{P}(E)$ females crossed with mars ${ }^{P}$ males were immunostained as described in the legend of Figure 4. In panel B, chromosomes aligned at spindle midzone before entering anaphase are indicated by a bracket above the embryo. Nuclei with delayed mitotic progression relative to neighboring nuclei at metaphase (C) or anaphase (D) are indicated by asterisks. The chromosome segregation in the tlk/mars embryos is very asynchronous (E). A white circle indicates a nucleus that is likely at metaphase based on the morphology of chromosomes. The scale bars without specification are $10 \mu \mathrm{m}$ 


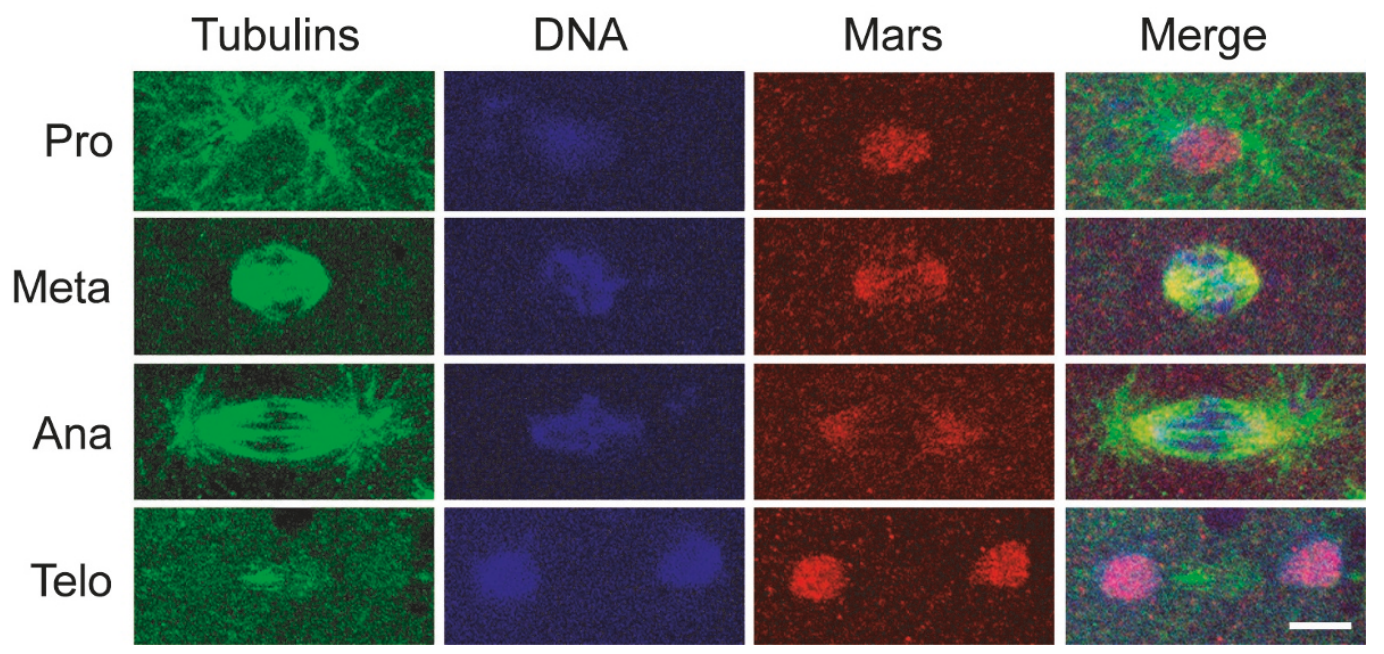

Figure 3

Mars localizes to mitotic spindles. $w^{1 / 18}$ embryos were immunostained with anti-Mars (red), anti- $\alpha-$ Tub (green) and anti- $\gamma$ Tub (green) antibodies. The chromosomes were stained by Hoechst 33342 (blue). The different phases of mitosis are indicated on the left. The scale bar is $5 \mu \mathrm{m}$.

\section{Hatching rate of mars ${ }^{P}$ embryos is reduced}

Located at 50A13-14, mars and downstream receptor kinase $(d r k)$ are transcribed in opposite directions and overlap by $36 \mathrm{bp}$. The insertion of $P\{E P\}$ at $23 \mathrm{bp}$ upstream of the putative start codon of mars in line $\operatorname{mars}^{P} / C \gamma O$ results in a hypomorphic mutation of mars [30]. Since the line obtained from the stock center is homozygous lethal, second-site lethal mutations were segregated out by meiotic recombination. The hatching rate of embryos from par-

Table I: Reduced fertility of mars alone and in combination with two tlk alleles

\begin{tabular}{|c|c|}
\hline Crosses (females $\times$ males) & Embryo hatching rate (\%) \\
\hline$w^{1 / 18} \times w^{1118}$ & $91.7 \pm 4.3$ \\
\hline $\operatorname{mars}^{R 160} \times$ mars $^{R 160}$ & $90.4 \pm 1.4$ \\
\hline$w^{1 / 18} ;$ mars $^{P} / d r k^{R I} \times w^{1 / 18} ;$ mars $^{P}$ & $96.4 \pm 2.6$ \\
\hline$w^{\prime / 18} ; \operatorname{mars}^{p} \times w^{\prime / 18}$ & $\begin{array}{c}95.8 \pm 2.2 \\
87.0 \pm 2.3^{a}\end{array}$ \\
\hline$w^{\prime / 18} ; \operatorname{mars}^{p} \times w^{\prime / 18} ;$ mars $^{p}$ & $\begin{array}{c}67.0 \pm 1.8 \\
39.2 \pm 4.3^{\mathrm{a}}\end{array}$ \\
\hline$w^{\prime / 1 / 8} ; \operatorname{mars}^{P} / D f(2 R) C X I \times w^{1 / 18}$ & 0 \\
\hline$w^{67 c 23} t / k^{27-9 /+} \times w^{1 / 18}$ & $97.0 \pm 1.1$ \\
\hline$w^{67 c 23} t / k^{4 / 4 /+} \times w^{1 / 18}$ & $93.3 \pm 0.9$ \\
\hline$w^{67 c 23}$ tlk $^{27-9 /+} ;$ mars $^{P} /+\times w^{1 / 18} ;$ mars $^{P}$ & $92.8 \pm 0.6$ \\
\hline$w^{67 c 23}$ tlk $^{414 /+;}$ mars $P /+\times w^{1 / 18} ;$ mars $^{P}$ & $\begin{array}{l}87.2 \pm 2.2 \\
77.5 \pm 3.3^{a}\end{array}$ \\
\hline$w^{67 c 23}$ tlk $^{27-9 /+} ;$ mars $^{P} \times w^{1 / 18} ;$ mars $^{P}$ & $48.0 \pm 1.6$ \\
\hline 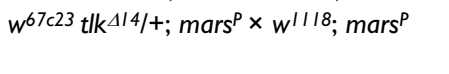 & $\begin{array}{c}63.8 \pm 2.2 \\
42.4 \pm 3.8^{a}\end{array}$ \\
\hline
\end{tabular}

Age of parents was 3-5 days. At least 600 embryos were scored to determine the hatching rate in each experiment.

a: Fertility was measured at the non-permissive temperature, $28.5 \pm$ $0.5^{\circ} \mathrm{C}$. ents homozygous for mars $^{P}$ (abbreviated as mars embryos hereafter) was $67.0 \%$, while those of embryos from females homozygous for $w^{1118}$ and heterozygous for $d r k^{R 1}$ and $\operatorname{mars}^{P}$ were 91.7 or $96.4 \%$, respectively (Table 1 ). The hatching rate was slightly higher than that reported by Tan et al. (49\%, [30]). Furthermore, the viability of the mars embryos was temperature-dependent and the hatching rate was further reduced to $39.2 \%$ at $28.5^{\circ} \mathrm{C}$. These results supported the fact that $\operatorname{mars}^{P}$ is a hypomorph and indicated that lethality is due to a shortage of both maternal and zygotic mars activity.

\section{mars loss-of-function decreases chromosome fidelity}

An organism that has a mixture of male and female characteristics is called as gynandromorph. Before sex is determined in a female embryo (X/X), loss of one sex chromosome during mitosis results in X/O cells that eventually lead to a male phenotype at the adult stage [36]. From $\operatorname{mars}^{P}$ parents, we found gynandromorphs formed approximately $0.05 \%$ of the progeny. Mars plays an important role to stabilize spindle microtubules, and its mutations thus result in the formation of abnormal spindle microtubules [30,38]. Similarly, it has been shown that nonclaret disjunctional loss-of-function causes defects in the mitotic spindle, which also results in gynandromorph [44]. Therefore, based on the above results, we examined morphology of mitotic spindles in mars embryos. 
A
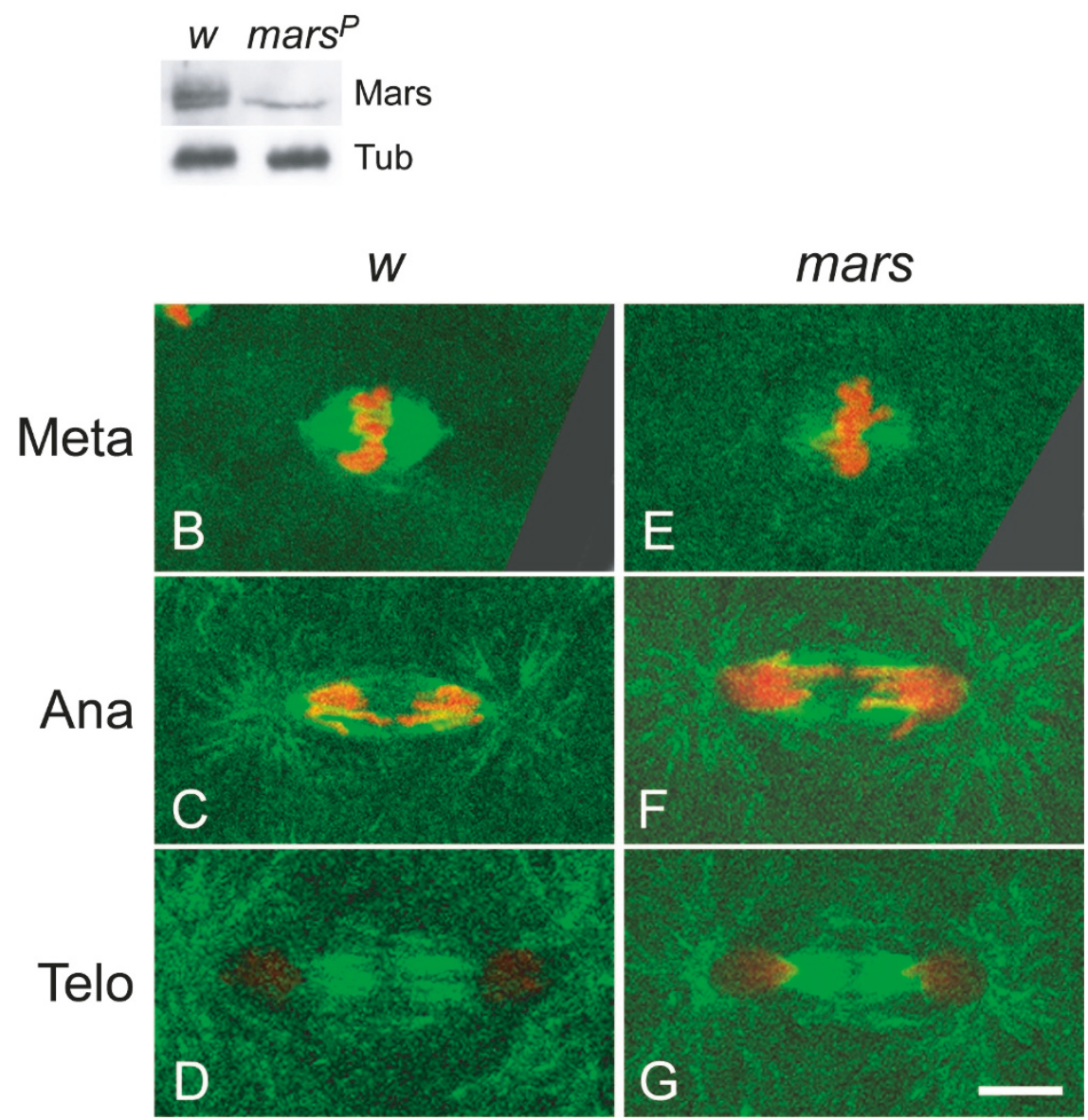

\section{Figure 4}

Embryos with reduced mars activity exhibit shorter and less dense mitotic spindles. (A) Immunoblotting of Mars protein extracted from 30 syncytial blastoderm embryos at metaphase with an anti-Mars antibody. A I35-kDa protein was detected and is labeled as Mars on the right. $\alpha$-Tub was served as the loading control. (B-G) Embryos at $28.5^{\circ} \mathrm{C}$ were immunostained with anti- $\alpha$-Tub (green) and anti- $\gamma$-Tub (green) and anti-phospho-histone $\mathrm{H} 3$ (red) antibodies. The morphology of the mitotic spindles at metaphase, anaphase and telophase in $w^{1 / 18}$ (B-D) and mars (E-G) embryos are shown. The scale bar is 5 $\mu \mathrm{m}$

\section{mars embryos exhibit delayed polymerization of mitotic spindles}

Yang and Fan have shown that two bands are detected in extracts from Drosophila S2 cells by immunoblotting with anti-Mars antibody and that the upper band consists of Mars that is phosphorylated [38]. To reveal whether both forms of Mars protein are differentially reduced in mars embryos, Mars protein in metaphase embryos was determined by immunoblotting. Using extracts from Drosophila embryos, reproducibly, two bands located close together and with equal intensity were able to be detected in this study (Fig. 4A); this differs from other studies, where a single band has been found [30,43]. In mars embryos, the amount of the unphosphorylated Mars, the lower band, was less than half of that in $w^{1118}$ embryos and the phosphorylated Mars was barely detectable (lane $\operatorname{mars}^{P}$ in Fig. $4 \mathrm{~A})$. These results plus the association of phosphorylated Mars with taxol-stabilized microtubules [38] indicated that the phosphorylated Mars, but not the unphosphorylated protein, is associated with mitotic spindles. The drastic reduction in phosphorylated Mars on the mitotic spindles might cause gynandromorphs to appear in progeny from parents homozygous for $\operatorname{mars}^{P}$.

Mitotic spindles in mars embryos from 1 to 2.5 hours at $28.5^{\circ} \mathrm{C}$ were examined using immunostaining with anti$\alpha$-Tub, anti- $\gamma$-Tub and anti-phospho-histone H3 antibodies. In metaphase mars embryos, the length and the den- 
Table 2: Mitotic index of embryos with reduced mars activity or tlk overexpression

\begin{tabular}{|c|c|c|c|c|c|c|c|}
\hline \multirow[b]{2}{*}{ Genotype of parents } & \multirow[b]{2}{*}{ Interphase } & \multicolumn{5}{|c|}{ Mitosis phases } & \multirow[b]{2}{*}{ Number of embryos } \\
\hline & & Pro & Meta & Ana & Telo & Mixed * & \\
\hline$w^{1118}$ & $59.3 \%$ & $10.9 \%$ & $23.2 \%$ & $3.1 \%$ & $2.0 \%$ & $1.5 \%$ & 543 \\
\hline $\operatorname{mars}^{P}$ & $49.9 \%$ & $17.4 \%$ & $17.1 \%$ & $11.2 \%$ & $0.4 \%$ & $4.0 \%$ & 546 \\
\hline GCN4>tlk\# & $39.2 \%$ & $15.1 \%$ & $25.0 \%$ & $5.3 \%$ & $12.6 \%$ & $2.8 \%$ & 602 \\
\hline
\end{tabular}

Embryos were immunostained with anti-histone $\mathrm{H} 3$ antibody and scored under a fluorescent microscope.

*: Embryos have at least two different mitotic phases. For examples, nuclei at the anterior of the embryo are at telophase whereas those at the posterior remain at metaphase.

\#: GCN4>tlk are from females carrying both UASP-tlk and GCN4-GAL4 transgenes mated with UAST-tlk males.

sity of mitotic spindles $(7.50 \pm 0.17 \mu \mathrm{m}$ and $28.53 \pm 3.31$ au) were significantly shorter and less, respectively, than those in $w^{1118}$ embryos $(11.98 \pm 0.16 \mu \mathrm{m}$ and $53.71 \pm 7.03$ au) (compare Fig. 4B with $4 \mathrm{E} ; p<0.001$ and 0.05 , respectively). At anaphase and at telophase, neither the length nor the density of mitotic spindles was substantially affected in the mars embryos (Figs 4C, D, F and 4G). These results indicated that the polymerization of the mitotic spindles in mars embryos is delayed, but not entirely prevented.

\section{Asynchronous chromosome segregation is observed in mars embryos}

Consistent with the fact that polymerization of mitotic spindles is affected in mars embryos, progression of mitotic events in patches of nuclei, each of which contained at least two nuclei, was obviously delayed comparing to those in adjacent nuclei (Figs 2C and 2D) in 13\% of mars embryos $(n=32)$. A possible explanation for these results is that the mitotic spindles lacking phosphorylated
Mars pull the chromosomes toward the spindle poles inefficiently, which results in both asynchronous chromosome segregation (Fig. 2D) and embryos pausing at anaphase (Table 2).

\section{Genetic interaction of mars with tlk is required for accurate chromosome segregation}

Without a proper genetic marker, identification of gynandromorphs is difficult if the $\mathrm{X} / \mathrm{O}$ cells do not locate to the posterior end of adult females. Therefore, $\operatorname{mars}^{P}$ males that also carry yellow $(y)$ and singed ( $s n)$ markers on the X chromosome were used to measure the gynandromorphy rate. Interestingly, the frequencies of non-disjunction, namely the ratios of $\mathrm{y}^{-} \mathrm{sn}^{-}$males to total males, in the male progeny from $w^{1118} ;$ mars $^{P}$ females crossed with $\gamma^{1} w^{1} s n^{3} ;$ mars $^{P}$ at $24^{\circ} \mathrm{C}$ and $28.5^{\circ} \mathrm{C}$ were $0.6 \%$ and $1.1 \%$, respectively (Table 3 ), which are much higher than the gynandromorphy rate in the mars parent. Hereafter, we measured the non-disjunction rate instead of gynandromorphy because it was a simpler procedure.

Table 3: The non-disjunction resulting from mars loss-of-function is enhanced by reduced tlk activity

\begin{tabular}{|c|c|c|}
\hline Genotype of mothers & Number of male progeny & $y^{-} w^{-} s^{-}$male progeny \\
\hline$w^{1118}$ & 979 & $0(0.0 \%)$ \\
\hline$w^{1 / 18} ; \operatorname{mars}^{P}$ & $\begin{array}{c}476 \\
374^{*}\end{array}$ & $\begin{array}{l}3(0.6 \%) \\
4(1.1 \%)\end{array}$ \\
\hline$w^{67 c 23} t / k^{27-9} / w^{1 / 18}$ & 579 & $0(0.0 \%)$ \\
\hline$w^{67 c 23} t / k^{414 / w^{1 / 18}}$ & $\begin{array}{c}909 \\
\left.107\right|^{*}\end{array}$ & $\begin{array}{l}\text { I }(0.1 \%) \\
4(0.4 \%)\end{array}$ \\
\hline$w^{67 c 23} t^{2} k^{27-9} / w^{1 / 18} ;$ mars $P /+$ & $\begin{array}{l}997 \\
636^{*}\end{array}$ & $\begin{array}{l}\text { I (0.1\%) } \\
\text { I (0.2\%) }\end{array}$ \\
\hline$w^{67 c 23}$ tlk $^{4 / 4} / w^{1 / 18} ;$ mars $^{P} /+$ & $\begin{array}{c}838 \\
1170^{*}\end{array}$ & $\begin{array}{l}0(0.0 \%) \\
3(0.3 \%)\end{array}$ \\
\hline$w^{67 c 23}$ tlk $^{27-9 / w^{1 / 18} ; \text { mars }^{p}}$ & $\begin{array}{c}398 \\
41 I^{*}\end{array}$ & $\begin{array}{c}5(1.2 \%) \\
25(6.1 \% \#)\end{array}$ \\
\hline$w^{1 / 18} t^{1 / k^{4 / 4} / w^{1 / 18} ; m a r s}{ }^{p}$ & $\begin{array}{c}926 \\
1188^{*}\end{array}$ & $\begin{array}{c}5(0.5 \%) \\
52(4.4 \% \#)\end{array}$ \\
\hline
\end{tabular}

Ten to twelve 2-day old females with the genotypes indicated in the left column were crossed with $y^{\prime} w^{\prime} s n^{3} ;$ mars ${ }^{P}$ males. Each cross was set up in at least five vials and transferred into new vials after three days. After the second transfer, the parents were discarded. The flies were incubated at $24^{\circ} \mathrm{C}$ or $28.5^{\circ} \mathrm{C} \pm 0.5^{\circ} \mathrm{C}$. The latter is indicated by an asterisk. Male progenies were counted for five consecutive days. The percentage of $y^{-} w^{-} s^{-}$ offspring over total males is shown in parenthesis. Number sign, \#, represents a significant difference between mars ${ }^{P}$ and $t / k^{27-9}$ or $\Delta / 4 /+;$ mars ${ }^{P}$ at $28.5^{\circ} \mathrm{C}$ as determined by the Student's $t$-test $(p<0.01)$. 
To test whether mars interacts with tlk genetically, dosagedependent interaction experiments were performed with two tlk alleles, $\Delta 14$ and 27-9. The hatching rate of embryos from $t^{27-9} /+$; $\operatorname{mars}^{P}$ females was $48 \%$, a further reduction from the $67 \%$ for mars embryos (Table 1), indicating that mars genetically interacts with tlk.

The frequencies of non-disjunction in male progenies from tlk $^{27-9} /+; \operatorname{mars}^{P}$ and $\operatorname{tlk}^{414} /+; \operatorname{mars}^{P}$ females at $28.5^{\circ} \mathrm{C}$ were $6.1 \%$ and $4.4 \%$; these rates were much higher than those from $\operatorname{mars}^{P}(1.1 \%)$ or $t k^{\Delta 14} /+$ females $(0.4 \%)$ (Table $3)$. This increase in frequency of non-disjunction was also temperature dependent, since there was no substantial increase in progeny from $t^{27-9} /+; \operatorname{mars}^{P}$ and $t k^{\Delta 14} /+$; mars $^{P}$ females $\left(1.2 \%\right.$ and $0.5 \%$, respectively) at $24^{\circ} \mathrm{C}$ when compared to $\operatorname{mars}^{P}$ or $t^{4} k^{\Delta 14} /+$ females. These results indicated that mars genetically interacts with tlk and that the interaction is involved in ensuring accurate chromosome segregation.

\section{mars acts in parallel to tlk during chromosome segregation}

To reveal whether mitosis is severely affected in embryos with reductions in both mars and tlk activity, embryos from $t_{k} k^{\Delta 14} /+;$ mars $^{P}$ females crossed to $\operatorname{mars}^{P}$ males (abbreviated as $t$ k/mars embryos) at $28.5^{\circ} \mathrm{C}$; these embryos were then immunostained using anti- $\alpha$-Tub, anti- $\gamma$-Tub and anti-phospho-histone $\mathrm{H} 3$ antibodies. A series of images along the $\mathrm{z}$ axis were stacked to observe the distribution of chromosomes and mitotic spindles. In embryos from females heterozygous for $t^{414}$, the chromosomes before entering anaphase were aligned at the spindle midzone as indicated by a bracket in Fig. 2B and the morphology of the mitotic spindles appeared normal $\left(t k^{414} /+\right.$; compare Fig. 2A with $4 \mathrm{~B})$. In almost all tlk/mars embryos at either metaphase or anaphase $(n=70)$, however, the asynchrony was so severe that it was impossible to distinguish what phase an embryo belonged to. In addition to the asynchrony that was observed in mars embryos (Fig. 2D), asynchronous chromosome segregation was observed in embryos where most of the nuclei were likely at anaphase (Fig. 2E). Despite the severe asynchrony during chromosome congression or segregation, the morphology of the mitotic spindles in tlk/mars embryos was not significantly different from that in mars embryos (compare Fig. 2E with 2C). These results suggested that mars acts in parallel to tlk.

To explore the parallel nature of the interaction between mars and tlk further, we tested whether the morphology of the mitotic spindles and Mars localization was affected in embryos overexpressing tlk. GCN4>tlk embryos at $24^{\circ} \mathrm{C}$ were immunostained with anti-Mars, anti- $\alpha$-Tub and anti$\gamma$-Tub antibodies. Images were processed as described above. Overexpression of $t l k$ induced a delayed progres- sion of mitotic events, which was manifest as several observable features similar to those seen in mars embryos. Firstly, the fraction of embryos at prophase was similar (Table 2). Secondly, patches of nuclei with delayed chromosome congression were seen in $30 \%$ of the metaphase embryos $(n=150)$ (Fig. 5B). Thirdly, at least one patch of nuclei exhibited delayed chromosome segregation with chromosome bridges in half of anaphase embryos $(\mathrm{n}=$ 32) (Fig. 5C). Despite the similarity of these effects to those observed in mars embryos, neither the length nor the density of most mitotic spindles at metaphase was substantially affected by tlk overexpression (compare Figs. $5 \mathrm{~A}$ with 5B). In agreement with this, tlk overexpression did not either affect the localization of Mars protein to mitotic spindles (Fig. 6) or decrease the quantity of acetylated tubulin (data not shown) that exists in the stable microtubules [2]. Taken together with the different subcellular localizations of Mars and Tlk, which localize to spindle microtubules and chromosomes respectively (this study; [17,30,43]), these results supported the notion that Mars functions in parallel to Tlk.

\section{Both mars and tlk activities are required for cells to correctly progress through chromosome segregation} Our previous results have shown that mars overexpression induces metaphase arrest in eye discs, with chromosomes attached to spindle monotelicaly in some cases [29]. Based on the role of Tlk-1 acting as a cofactor of Aur-B $[3,19,23]$, we next asked the question whether $t$ lk overexpression could overcome the metaphase arrest. To test this, we counted M-phase cells in the three different domains behind morphogenetic furrow (MF) as classified by Baker and Yu (2001) [45]. Reproducibly, mars overexpression resulted in cells in domain I being retained at interphase and in many cells in domains II and III being retained at $M$-phase (Figs. $7 \mathrm{~B}$ and $7 \mathrm{E}$ ); this should be compared with the fact that most $M$-phase cells appear in domain I of $w^{1118}$ discs (Fig. 7A and 7E). Similarly, tlk overexpression induced a delayed progression of mitosis, but to a lesser extent (Figs. 7C and 7E). When both genes were co-overexpressed, the number of $\mathrm{M}$-phase cells in domain III was reduced to a level close to that of the wildtype, showing that the metaphase arrest induced by mars overexpression was suppressed by tlk overexpression (Fig. 7E). These results indicated that a balance between mars and tlk activities is required for cells to progress through mitosis correctly.

\section{Discussion}

In this study, we have examined the genetic interaction between mars and tlk in terms of chromosome fidelity. Progeny from mars parents showed a low percentage of gynandromorphs and non-disjunction. The decreased fidelity is a result of delayed polymerization of mitotic spindles as shown by shorter and thinner mitotic spindles 


\section{GCN4>GFP}
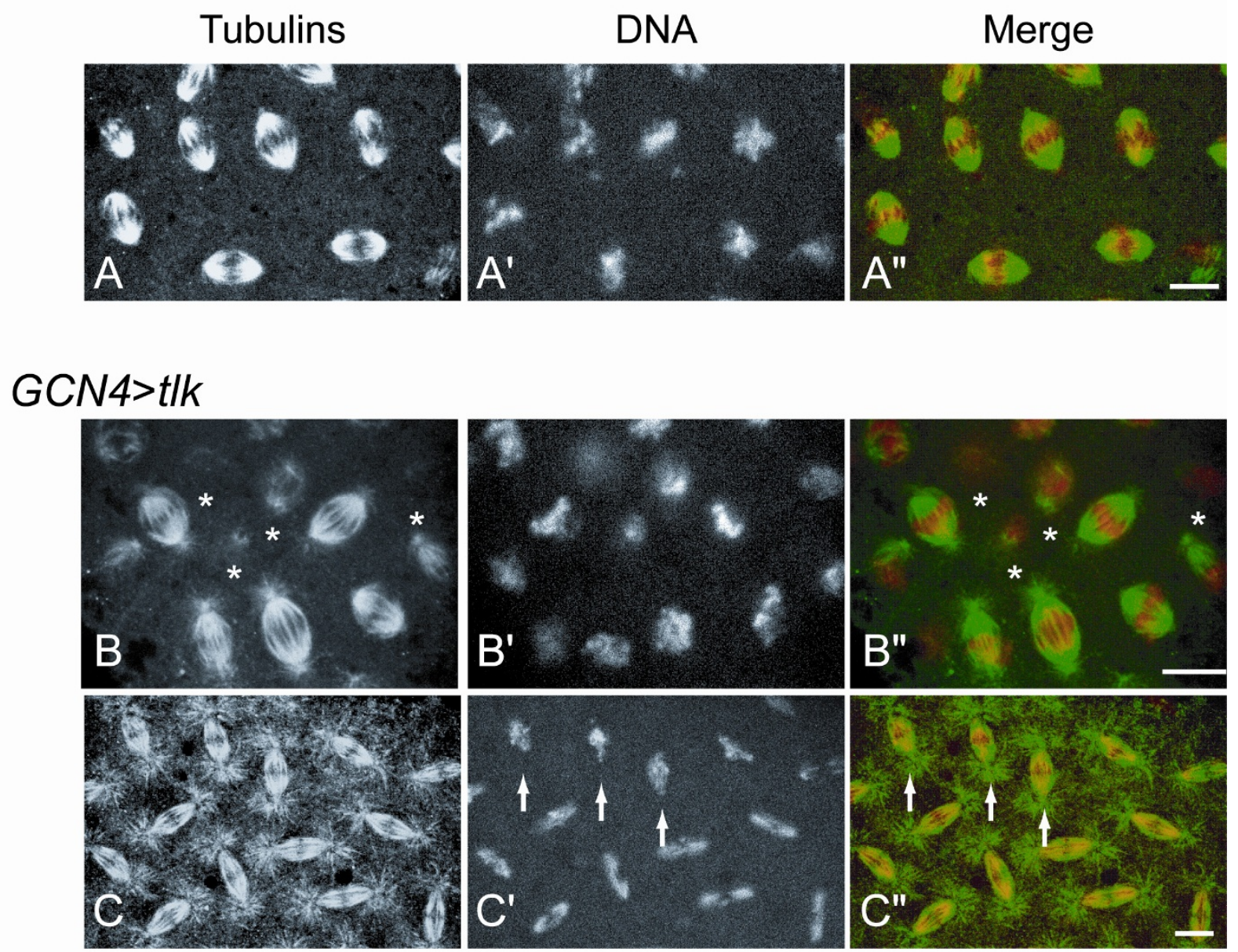

\section{Figure 5}

Mitotic defects in embryos with tlk overexpression are similar to those observed in mars embryos. Embryos with either GFP (GCN4>GFP) or tlk overexpression (GCN4>tlk) at $28.5^{\circ} \mathrm{C}$ were immunostained with anti- $\alpha$-Tub (green) and anti- $\gamma$ Tub (green) antibodies. The chromosomes were stained by Hoechst 33342 (red). (A) GFP overexpression in metaphase embryo serves as a negative control. (B) Most of the mitotic spindles were normal in metaphase embryos when tk was overexpressed. A few nuclei showed corrupted mitotic spindles that also appear to have less chromosomal DNA and these are indicated by asterisks. (C) A patch of nuclei with less condensed chromosomes at anaphase is indicated by arrows and the chromosomes seem to remain unseparated. These two phenotypes were also observed in GCN4>tlk embryos at $24^{\circ} \mathrm{C}$. The scale bars are $10 \mu \mathrm{m}$.

in embryos with reduced mars activity, which is consistent with the recent findings reported by Tan et al [30]. In addition, the non-disjunction rate was significantly increased by removing one copy of tlk at the non-permissive temperature.

Tlk is a substrate and cofactor of Aur-B, which is a chromosome passenger protein and localizes to centromeres during the prophase to metaphase-to-anaphase transition $[3,19,23]$. Aur-B destabilizes kinetochore-bound microtubules locally to promote syn-to-amphitelic attachment
$[24,46,47]$. Microtubule dynamics are important for the assembly of mitotic spindles, as well as for the segregation of chromosomes captured by the mitotic spindles at kinetochores $[48,49]$. Our results showed that $t l k$ overexpression suppresses the metaphase arrest induced by mars overexpression. This metaphase arrest is a result of abnormal polymerization of mitotic spindles, resulting in the syntelic or monotelic attachment in some cases [29]. The fact that Tlk-1 mediates the activation of Aur-B kinase [3] provides an explanation. It is likely that Aur-B kinase activity is elevated by $t l k$ overexpression, which destabi- 


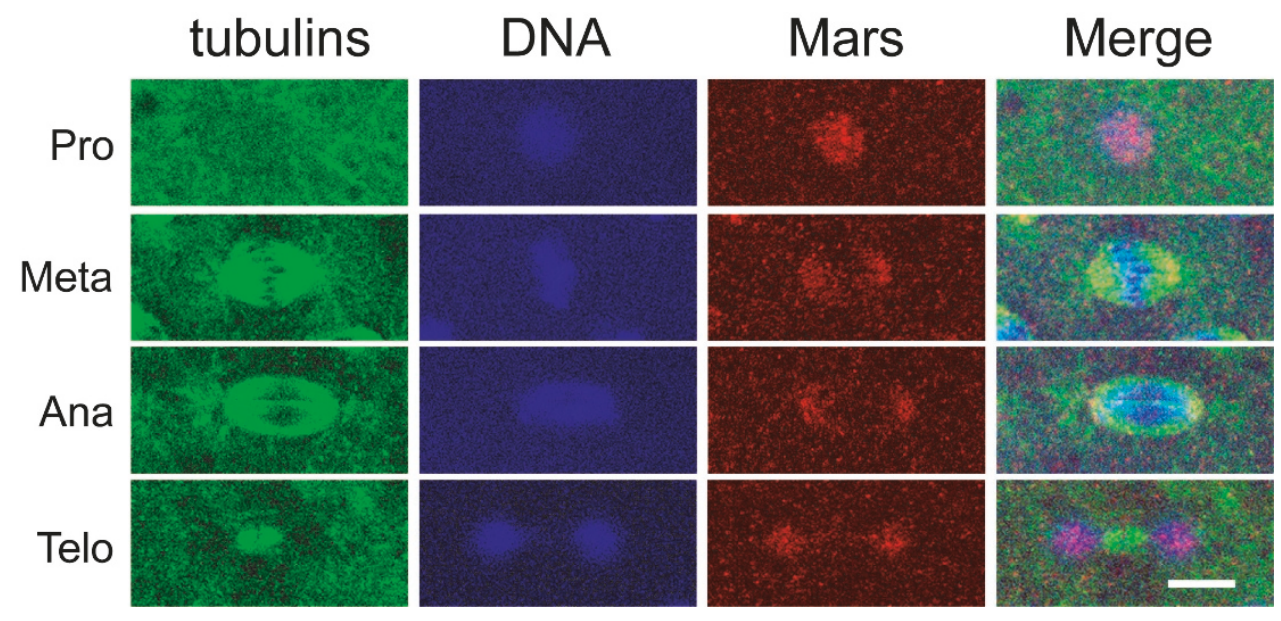

\section{Figure 6}

Localization of Mars on mitotic spindles is unaffected by $t / k$ overexpression. Embryos at $28.5^{\circ} \mathrm{C}$ from $\mathrm{GCN} 4>t / k$ females crossed with UAST-tlk males were immunostained with anti-Mars (red), anti- $\alpha$-Tub (green) and anti- $\gamma$-Tub (green) antibodies. The chromosomes were stained with Hoechst 33342 (blue). The Mars patterns in GCN4>tlk embryos at prophase, metaphase, anaphase and telophase are similar to those in $w^{1 / 18}$ embryos (Fig. I). The scale bar is $5 \mu \mathrm{m}$.
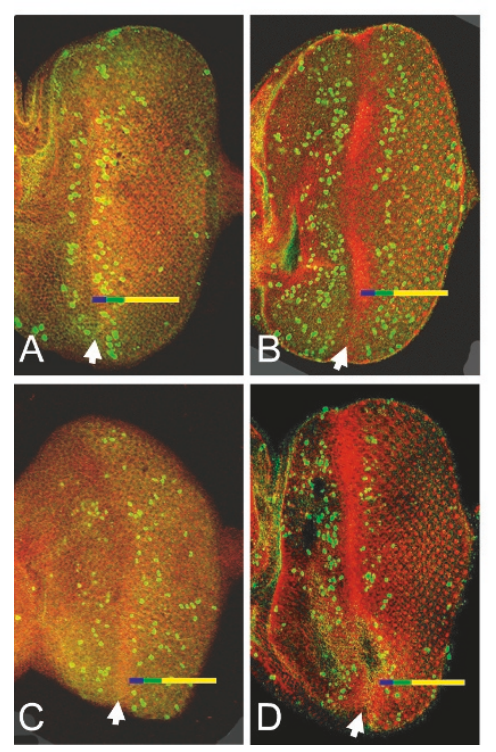

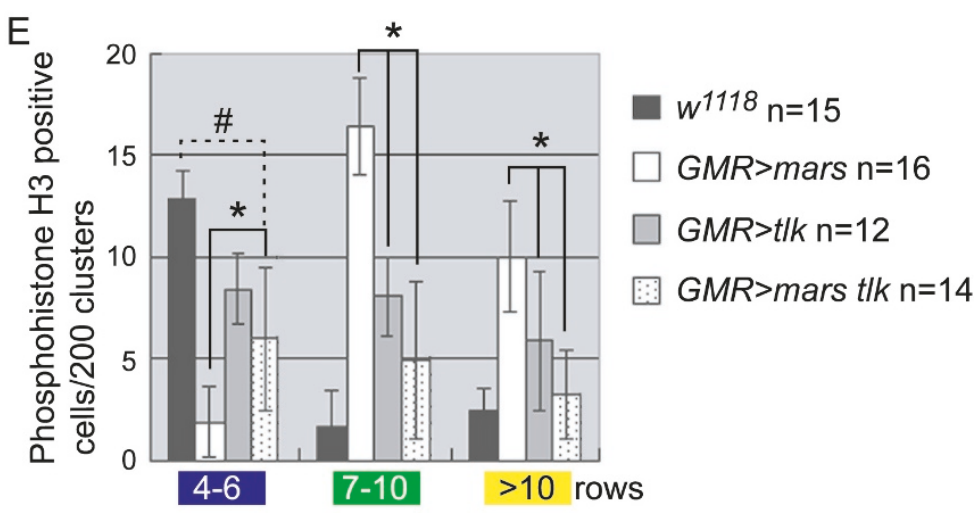

Figure 7

The M-phase arrest induced by mars overexpression is suppressed by $\mathbf{t} \mathbf{k}$ overexpression. Eye-antennal discs were dissected from the third-instar larvae and immunostained with anti-phospho-histone $\mathrm{H} 3$ antibody (green) and phalloidin (red) to label the M-phase cells and the neuronal clusters, respectively. The genotypes for panel $A$ to $D$ are $w^{\prime l l 8}(A), G M R>m a r s(B)$, $G M R>$ tlk (C)and GMR>mars tlk (D). The anterior of the discs is arranged toward the left. The arrows indicate the morphogenetic furrows (MF). The region behind the MF is divided into three distinct domains, namely I (4-6), II (7-I0) and III (>II rows of neuronal clusters), as described by Baker and $\mathrm{Yu}(200 \mathrm{I})$ [45]. The color codes for the three domains are blue, green and red for domains I, II and III, respectively. (E) From each disc, the M-phase cells in two hundred clusters (I0 clusters parallel and 20 clusters perpendicular to MF) were measured and plotted as a histogram. The representation and number of discs measured for each column are shown on the right. The statistical significance of M-phase cells presenting in the three regions was determined using the Student's $t$-test. The numbers of M-phase cells in the eye discs with overexpression of both mars and tlk differ significantly from those overexpressing mars or $t / k$ alone and are also different from the $w^{1 / 18}$ discs. These differences are indicated by asterisks and \#, respectively $(p<0.05)$. 
lizes kinetochore-bound microtubules more rapidly; this counteracts the polymerization of mitotic spindles induced by mars overexpression. This will result in the suppression of the metaphase arrest. The local rapid-turnover of microtubules induced by the increased Aur-B activity may also cause deterioration in the spindle microtubules bound to kinetochores, which could lead to asynchrony without an obvious effect on the mitotic spindles in embryos overexpressing tlk. Therefore, Mars and Tlk function to promote polymerization of the mitotic spindle and to elevate Aur-B kinase activity, respectively. Both are important for the syntelic-to-amphitelic transition, this hypothesis being supported by the increase in nondisjunction and the observation of more severe asynchrony when both gene activities were reduced. Nevertheless, determination of the epistatic relationship between aur-B and tlk awaits suitable aur-B mutants.

Our results showed that a mars hypomorph exhibits subtle defects in chromosome fidelity and viability, which are temperature dependent. Little or no phenotype has been reported for loss-of-function mutants in many comprehensive studies, such as the hhoA gene in bacteria [50], the $P P H 21, M D M 17$ and ISS1 genes in yeast [51-53] and the Suppressor of fused gene in fly [54]. These phenotypes then become more obvious when the organism is incubated at an elevated temperature and/or when one copy of an interacting locus is removed. The products of these genes are either components or redundant factors in protein complexes. For example, deletion of the ISS1 gene has no significant effect on yeast growth; however, when combined with sec24, which codes for a component in the vSNARE complex, the combination of iss 1 and sec 24 in yeast becomes lethal. Furthermore, iss 1 overexpression is able to suppress the mutation in sec24, indicating that Iss 1 can replace Sec24 [51]. In a similar way, the enhancement of the mild mitotic defects in flies caused by reduced mars activity when the incubation temperature is elevated or when one copy of $t$ lk is removed suggests that both Mars and Tlk proteins participate together in one or more protein complexes that are required for chromosome segregation.

\section{Conclusion}

This study showed that there was a low but significant rate of gynandromorphy and non-disjunction in progeny from parents homozygous for mars, which indicates that Mars is required for accurate chromosome segregation. The decreased fidelity was due to an inability to polymerize mitotic spindles correctly and this led to chromosome aberrations in embryos with reduced mars activity. Chromosome fidelity was significantly decreased to a further extent when one copy of tlk was removed in addition to the reduction in mars activity. The results from cytological studies indicated that mars acts in parallel to tlk and that a balance between mars and tlk activity is required for cells to progress through mitosis correctly and ensure chromosome fidelity.

\section{Competing interests}

The authors declare that they have no competing interests.

\section{Authors' contributions}

HHL carried out most of the experiments and provided valuable inputs into the manuscript. HYH observed the nuclear cleavage in embryos with reduced mars activity by the time-lapse recording and found the inaccurate chromosome segregation, which led to the finding on gynandromorphy and non-disjunction. Both CSC and GJL participated in design of the study and writing the manuscript. GJL also performed part of the experiments. All authors have read and approved the final manuscript.

\section{Acknowledgements}

We acknowledge the use by us of the confocal microscope (Leica TSC-SP2) in the Imaging Core Facility of Nanotechnology of UST-YMU and of the flyfood facility in Dr. Y. H. Sun's laboratory, the Institute of Molecular Biology, Academia Sinica. This work was supported by a grant from the Ministry of Education, Aim for the Top University Plan and NSC grants to GJL, 93-962752-B-010-005-PAE.

\section{References}

I. Wong J, Lerrigo R, Jang CY, Fang G: Aurora A Regulates the Activity of HURP by Controlling the Accessibility of Its Microtubule-binding Domain. Mol Biol Cell 2008, 19:2083-209I.

2. Piperno $G$, LeDizet $M$, Chang $X$ J: Microtubules containing acetylated alpha-tubulin in mammalian cells in culture. J Cell Biol 1987, 104:289-302.

3. Riefler GM, Dent SY, Schumacher JM: Tousled-mediated activation of Aurora B kinase does not require Tousled kinase activity in vivo. J Biol Chem 2008, 283: I 2763-I2768.

4. Zheng L, Chen Y, Riley D, Chen P, Lee W: Retinoblastoma protein enhances the fidelity of chromosome segregation mediated by hsHeclp. Mol Cell Biol 2000, 20:3529-3537.

5. Edgerton ME, Taylor R, Powell JI, Hunter L, Simon R, Liu ET: A bioinformatics tool to select sequences for microarray studies of mouse models of oncogenesis. Bioinformatics 2002, I 8:774-775.

6. Yu CT, Hsu JM, Lee YC, Tsou AP, Chou CK, Huang CY: Phosphorylation and stabilization of HURP by Aurora-A: implication of HURP as a transforming target of Aurora-A. Mol Cell Biol 2005, 25:5789-5800.

7. Tsou AP, Yang CW, Huang CY, Yu RC, Lee YC, Chang CW, Chen $B R$, Chung YF, Fann MJ, Chi CW, et al.: Identification of a novel cell cycle regulated gene, HURP, overexpressed in human hepatocellular carcinoma. Oncogene 2003, 22:298-307.

8. Caruana G: Genetic studies define MAGUK proteins as regulators of epithelial cell polarity. Int J Dev Biol 2002, 46:5 I I-5 I8.

9. Sheng M, Kim E: The Shank family of scaffold proteins. J Cell Sci 2000, I I 3:1851-1856.

10. Tepass U, Tanentzapf G, Ward R, Fehon R: Epithelial cell polarity and cell junctions in Drosophila. Annu Rev Genet 200I, 35:747-784.

II. Tsai MY, Wiese C, Cao K, Martin O, Donovan P, Ruderman J, Prigent C, Zheng Y: A Ran signalling pathway mediated by the mitotic kinase Aurora A in spindle assembly. Nat Cell Biol 2003, 5:242-248.

12. Sillje HH, Nagel S, Korner R, Nigg EA: HURP is a Ran-importin beta-regulated protein that stabilizes kinetochore microtubules in the vicinity of chromosomes. Curr Biol 2006, I 6:73|-742. 
13. Koffa MD, Casanova CM, Santarella R, Kocher T, Wilm M, Mattaj IW: HURP is part of a Ran-dependent complex involved in spindle formation. Curr Biol 2006, 16:743-754.

14. Wong J, Fang G: HURP controls spindle dynamics to promote proper interkinetochore tension and efficient kinetochore capture. J Cell Biol 2006, I 73:879-89I.

15. Santarella RA, Koffa MD, Tittmann P, Gross H, Hoenger A: HURP wraps microtubule ends with an additional tubulin sheet that has a novel conformation of tubulin. J Mol Biol 2007, 365: $1587-1595$.

16. Roe JL, Rivin CJ, Sessions RA, Feldmann KA, Zambryski PC: The Tousled gene in $A$. thaliana encodes a protein kinase homolog that is required for leaf and flower development. Cell 1993, 75:939-950.

17. Carrera P, Moshkin YM, Gronke S, Sillje HH, Nigg EA, Jackle H, Karch F: Tousled-like kinase functions with the chromatin assembly pathway regulating nuclear divisions. Genes Dev 2003, 1 7:2578-2590.

18. Han Z, Saam JR, Adams HP, Mango SE, Schumacher JM: The C. elegans Tousled-like kinase (TLK-I) has an essential role in transcription. Curr Biol 2003, I3:1921-1929.

19. Li Z, Gourguechon S, Wang CC: Tousled-like kinase in a microbial eukaryote regulates spindle assembly and S-phase progression by interacting with Aurora kinase and chromatin assembly factors. J Cell Sci 2007, I 20:3883-3894.

20. Sillje HH, Takahashi K, Tanaka K, Van Houwe G, Nigg EA: Mammalian homologues of the plant Tousled gene code for cellcycle-regulated kinases with maximal activities linked to ongoing DNA replication. Embo J 1999, I 8:569|-5702.

21. Sunavala-Dossabhoy G, Li Y, Williams B, De Benedetti A: A dominant negative mutant of TLKI causes chromosome missegregation and aneuploidy in normal breast epithelial cells. BMC Cell Biol 2003, 4:16

22. Sillje $\mathrm{HH}$, Nigg EA: Identification of human Asf I chromatin assembly factors as substrates of Tousled-like kinases. Curr Biol 2001, I I: 1068-1073.

23. Han Z, Riefler GM, Saam JR, Mango SE, Schumacher JM: The C. elegans Tousled-like kinase contributes to chromosome segregation as a substrate and regulator of the Aurora B kinase. Curr Biol 2005, I 5:894-904.

24. Andrews PD, Knatko E, Moore WJ, Swedlow JR: Mitotic mechanics: the auroras come into view. Curr Opin Cell Biol 2003, I 5:672-683.

25. Compton DA: Spindle assembly in animal cells. Annu Rev Biochem 2000, 69:95-114.

26. Bennett D, Alphey L: Cloning and expression of mars, a novel member of the guanylate kinase associated protein family in Drosophila. Gene Expr Patterns 2004, 4:529-535

27. Gates J, Thummel CS: An enhancer trap screen for ecdysoneinducible genes required for Drosophila adult leg morphogenesis. Genetics 2000, I 56: I765-I776.

28. Hsu JM, Lee YC, Yu CT, Huang CY: Fbx7 functions in the SCF complex regulating CdkI-cyclin B-phosphorylated Hepatoma Up-Regulated Protein (HURP) proteolysis by a proline-rich region. J Biol Chem 2004, 279:32592-32602.

29. Yang CP, Chen MS, Liaw GJ, Chen SF, Chou G, Fan SS: Using Drosophila eye as a model system to characterize the function of mars gene in cell-cycle regulation. Exp Cell Res 2005, 307: $183-193$.

30. Tan S, Lyulcheva E, Dean J, Bennett D: Mars promotes dTACC dephosphorylation on mitotic spindles to ensure spindle stability. J Cell Biol 2008, I 82:27-33.

31. Olivier JP, Raabe T, Henkemeyer M, Dickson B, Mbamalu G, Margolis B, Schlessinger J, Hafen E, Pawson T: A Drosophila SH2-SH3 adaptor protein implicated in coupling the sevenless tyrosine kinase to an activator of Ras guanine nucleotide exchange, Sos. Cell 1993, 73:179-191.

32. Rorth P: Gal4 in the Drosophila female germline. Mech Dev 1998, 78:113-118.

33. Rubin GM, Spradling AC: Vectors for $\mathbf{P}$ element-mediated gene transfer in Drosophila. Nucleic Acids Res 1983, I I:634 I-635 I.

34. Spradling AC, Rubin GM: The effect of chromosomal position on the expression of the Drosophila xanthine dehydrogenase gene. Cell 1983, 34:47-57.

35. Janody F, Reischl J, Dostatni N: Persistence of Hunchback in the terminal region of the Drosophila blastoderm embryo impairs anterior development. Development 2000, | 27: | 573-1582

36. Greenspan RJ: Fly pushing: The theory and practice of Drosophila genetics 2nd edition. New York: Cold Spring Harbor Laboratory Press; 2004.

37. Su TT: Immunoblotting fo proteins from single Drosophila embryos. In Drosophila protocols Edited by: Sullivan W, Ashbourner M, Hawley RS. New York: Cold Spring Harbor Laboratory Press; 2000:577-583

38. Yang CP, Fan SS: Drosophila mars is required for organizing kinetochore microtubules during mitosis. Exp Cell Res 2008, 3 | 4:3209-20.

39. Rothwell WF, Sullivan W: Fluorescent analysis of Drosophila embryos. In Drosophila Protocols Edited by: Sullivan W, Ashbourner M, Hawley RS. New York: Cold Spring Harbor Laboratory Press; 2000:141-157.

40. Blair SS: Imaginal discs. In Drosophila protocols Edited by: Sullivan W, Ashbourner M, Hawley RS. New York: Cold Spring Harbor Laboratory Press; 2000: I59-I73.

41. Goodman B, Zheng Y: Mitotic spindle morphogenesis: Ran on the microtubule cytoskeleton and beyond. Biochem Soc Trans 2006, 34:7l6-72I.

42. May KM, Hardwick KG: The spindle checkpoint. J Cell Sci 2006, I 1 9:4139-4|42.

43. Zhang G, Breuer M, Forster A, Egger-Adam D, Wodarz A: Mars, a Drosophila protein related to vertebrate HURP, is required for the attachment of centrosomes to the mitotic spindle during syncytial nuclear divisions. J Cell Sci 2009, I 22:535-545.

44. Endow SA, Chandra R, Komma DJ, Yamamoto AH, Salmon ED: Mutants of the Drosophila ncd microtubule motor protein cause centrosomal and spindle pole defects in mitosis. J Cell Sci 1994, I 07(Pt 4):859-867.

45. Baker NE, Yu SY: The EGF receptor defines domains of cell cycle progression and survival to regulate cell number in the developing Drosophila eye. Cell 2001, 1 04:699-708.

46. Tanaka TU, Rachidi N, Janke C, Pereira G, Galova M, Schiebel E, Stark MJ, Nasmyth K: Evidence that the IpII-Sli 5 (Aurora kinaseINCENP) complex promotes chromosome bi-orientation by altering kinetochore-spindle pole connections. Cell 2002, 108:317-329.

47. Vader G, Medema RH, Lens SM: The chromosomal passenger complex: guiding Aurora-B through mitosis. J Cell Biol 2006, 1 73:833-837.

48. Biggins S, Walczak CE: Captivating capture: how microtubules attach to kinetochores. Curr Biol 2003, I3:R449-460.

49. Cleveland DW, Mao Y, Sullivan KF: Centromeres and kinetochores: from epigenetics to mitotic checkpoint signaling. Cell 2003, I I 2:407-42 I.

50. Gottesman S: Proteases and their targets in Escherichia coli. Annu Rev Genet 1996, 30:465-506.

5I. Kurihara T, Hamamoto S, Gimeno RE, Kaiser CA, Schekman R, Yoshihisa $T$ : Sec24p and IssIp function interchangeably in transport vesicle formation from the endoplasmic reticulum in Saccharomyces cerevisiae. Mol Biol Cell 2000, I I:983-998.

52. Shepard KA, Yaffe MP: The yeast dynamin-like protein, Mgm I p, functions on the mitochondrial outer membrane to mediate mitochondrial inheritance. / Cell Biol 1999, | 44:71 |-720.

53. Yang $H$, Jiang $W$, Gentry $M$, Hallberg RL: Loss of a protein phosphatase $2 \AA$ regulatory subunit (Cdc55p) elicits improper regulation of Swelp degradation. Mol Cell Biol 2000, 20:8|43-8I56.

54. Stegman MA, Vallance JE, Elangovan G, Sosinski J, Cheng Y, Robbins DJ: Identification of a tetrameric hedgehog signaling complex. J Biol Chem 2000, 275:21809-21812. 